\title{
"PARA LIVRAR DE TODO CATIVEIRO E PERSEGUIÇÃO”: LIBERDADE DE ESCRAVOS ATRAVÉS DE CARTAS DE ALFORRIA EM LARANJEIRAS, SERGIPE (1843-1881)
}

\section{Luiz Paulo Santos Bezerra ${ }^{1}$}

Resumo: No presente texto, pretende-se fazer uma análise descritiva de um conjunto de cartas de alforria registradas nos Livros de Notas de Laranjeiras, Sergipe, durante os períodos de 1843 a 1881. Esses registros de liberdade nos fornecem dados importantes sobre os escravos e senhores que viveram na zona do Cotinguiba, mais precisamente em Laranjeiras, onde o seu desenvolvimento econômico foi de grande relevância para Sergipe. Os resultados encontrados nesta pesquisa são parciais, pois, para uma melhor compreensão será necessário ainda, um cruzamento de outras fontes como, os inventários e testamentos post-mortem da mesma localidade. Dialogamos ainda com vários autores que tratam do mesmo tema em outras regiões do Brasil.

Palavras-chave: Escravidão, Cartas de alforria, Laranjeiras/SE.

\section{Introdução:}

É notório no Brasil o crescente número de historiadores que tratam de analisar variados tipos de fontes documentais para entender os proces-

\footnotetext{
${ }^{1}$ Graduando do $7^{\circ}$ período de História da Universidade Federal do Sergipe. Bolsista do Programa de Educação Tutorial (PET/História/UFS). Orientando do Prof. Dr. Itamar de Freitas do Departamento de Educação e do Núcleo de PósGraduação em Educação da Universidade Federal de Sergipe. Lattes: http://buscatextual.cnpq.br/buscatextual/visualizacv.do?id=S3582708
} 
sos de liberdade dos escravos em diferentes regiões do país. Entre os muitos registros, as cartas de alforria se encontram como fundamentais para o desenvolvimento desses estudos. E apesar da historiografia da escravidão e do processo de manumissão ser bastante rica, em Sergipe há uma carência de trabalhos que se preocupem em analisar tal documentação cartorial. Assim, neste trabalho analisaremos um conjunto de cartas de alforrias que foram encontradas no Arquivo do Judiciário do Estado de Sergipe.

Dentro de uma carta de alforria, o historiador poderá escolher o que se estudar, pois há várias possibilidades de análise deste material. Assim sendo, tentaremos mostrar como os escravos da região de Laranjeiras-SE estão representados, além de trazer outras características fundamentais para o entendimento das alforrias. São elas: o sexo dos escravos, o sexo dos senhores, a idade destes cativos, a tipologia das cartas e as denominações desses escravos nas cartas de alforrias.

O corpo documental utilizado na presente pesquisa é formado por 27 registros de cartas de liberdade encontrados nos Livros de Notas de Laranjeiras durante os respectivos períodos: 1843-45, 1859-60, 1871 e após este último período, somente encontramos os Livros referentes ao ano de 1881. Deste modo, o desenvolvimento da pesquisa está condicionado a uma considerável barreira: parte significativa da documentação não pode ser analisada devido à precariedade de sua conservação, logo, ela está vedada à análise. Por falta de alguns dados, ficamos impossibilitados de darmos algumas informações precisas, como a ocupação dos escravos e locais de residência dos seus senhores. É possível que, cruzando outras fontes, como os inventários e testamentos post-mortem, esses dados se complementem e nos ofereça uma maior precisão na pesquisa. 
Este trabalho encontra-se divido em duas partes, além da introdução e conclusão. No tópico intitulado A região do Cotinguiba e a dinâmica da escravidão vamos tratar em apresentar a região em que as cartas de alforrias foram outorgadas. E por último, em O perfil das cartas de alforria em Laranjeiras será analisado os principais aspectos encontrados nesse conjunto de documentação cartorial.

\section{A região do Cotinguiba e a dinâmica da escravidão:}

Situada na zona do Cotinguiba, dominada pela cultura da cana-deaçúcar devido à sua localização e por possuir uma terra propícia ao cultivo durante o período oitocentista, Laranjeiras surge como um dos principais centros políticos e econômicos da Província de Sergipe. Por tais características, essa região concentrou um grande contingente de mão-de-obra negra/escrava, moldando-se a uma sociedade de cunho agrárioescravocrata.

Utilizando diversas fontes, Luiz Mott (1986, p. 192) diz que em 1856 a população sergipana era de 134.124 pessoas. Deste total, 32.741 formavam o plantel de escravos. No mesmo período, Sergipe contava com aproximadamente 724 engenhos. Grande parte destes estava localizada na região do Cotinguiba, que contava com 402 engenhos. Esse número aumentou ainda mais com o passar dos anos. Estes dados econômicos e quantitativos dão o quadro maior para entendermos a dinâmica das alforrias em Laranjeiras. Comportando uma quantidade significativa de mãode-obra escrava, é provável que as taxas de alforria também fossem altas.

Mas, analisando a tese de Sharyse Piroupo (2007), cujos estudos voltaram-se para a mesma região, percebemos que a autora chega a con- 
clusão de que nessa zona canavieira, apesar de ter existido um considerável plantel de escravos, aquela quantidade não conseguiu dar conta de toda uma rotina diária necessária para a manutenção dos engenhos. Pensando assim, se falta mão-de-obra para o trabalho, as taxas de alforria também poderiam ser baixas ${ }^{2}$. A região do Cotinguiba também não iria sentir o golpe do tráfico interprovincial, momento em que vários escravos de regiões diversas do país, principalmente do Norte/Nordeste, saíram para as fazendas de café no sul do Brasil. No auge desse novo negócio, a região foi importadora desses cativos e utilizou razoavelmente a mão-deobra livre.

A carta de alforria foi um dos dispositivos legais em que os escravos poderiam se apoiar, caso tivessem uma “boa relação” para com o seu senhor. Pois, sabemos que antes da Lei Rio Branco, conhecida popularmente como a Lei do Ventre Livre, de 1871, não havia uma lei específica que permitisse ao cativo juntar seu pecúlio e comprar sua carta de alforria, exigindo assim do mesmo escravo um trabalho obediente, servindo anos a fio ao seu senhor. E por isso, talvez, essa relação entre ambas as partes fizesse com que demorasse décadas para que de alguma forma o ganho da liberdade se concretizasse. No entanto, vários escravos conseguiram antes mesmo da citada lei suas alforrias, através de várias estratégias, seja trabalhando nas ruas, recebendo doações de algumas instituições, via testamen-

\footnotetext{
${ }^{2}$ Infelizmente, as cartas de alforrias analisadas não forneceram indícios sobre este aspecto.
} 
to, ou em ações de liberdade movidas contra os seus senhores ${ }^{3}$. Um caso típico dessa "boa relação” entre o senhor e seus escravos está na carta de alforria outorgada no Engenho Coqueiro em Laranjeiras no ano de 1860:

Digo eu João Pinto de Resendes senhor e possuidor que sou de uma mulata de nome senhoria, que tem vinte e cinco annos de idade que a estimo no valor de hum conto de réis, a qual mulata em obtenção aos bons serviços prestados, por minha morte deixo a forra sem condição alguma, sendo seu valor imputado na minha herança $[\ldots]^{4}$ [grifo nosso].

Neste trecho da carta de alforria conferida pelo senhor Resendes a sua escrava mulatinha dentre os vários aspectos podemos destacar a frase “aos bons serviços prestados”. De acordo com os autores que com frequência estamos dialogando neste trabalho é comum encontrar essa frase nas cartas de alforrias, principalmente quando ela é “doada” por seu senhor. Talvez aqui, estamos diante de uma das possíveis estratégias desses donos de escravos para tentar assegurar por mais alguns anos o trabalho obediente de sua cativa, deixando claro que se o escravo trabalhar de forma obediente poderá, um dia, ser contemplado por seu dono e ganhar a tão sonhada liberdade. Vale ressaltar que estamos descrevendo um fato do inicio da segunda metade do século XIX, onde as brechas para se livrar do

${ }^{3} \mathrm{O}$ trabalho de Sidney Chalhoub em Visões da liberdade: uma história das últimas décadas da escravidão na corte é revelador quanto às possibilidades dos escravos conseguir ganhar a liberdade através de ações legais movida contra os seus senhores.

${ }^{4}$ Registro da carta de liberdade conferida por João Pinto de Resendes a sua escrava de nome senhoria mulata. AJES, caixa 250, fl. 95. 
Cadernos de Clio, Curitiba, n. ${ }^{\circ}$ 4, 2013

cativeiro eram bem pequenas, o que deixa o escravo a depender, ainda mais, dessa "boa relação” para com o seu senhor.

Segundo alguns autores, como Kátia Mattoso, Mary Karasch e Sidney Chalhoub, as mulheres foram as que mais receberam cartas de alforria. A resposta para isso talvez esteja nos seus baixos preços em comparação aos homens, os laços afetivos para com seus senhores, e por estarem às vezes em funções do lar, próximas de suas senhoras. Todos esses fatores podem ter facilitado os seus arranjos e consequentemente uma maior chance em obter a carta de alforria. Já os homens, por serem bem mais preferidos pela sua qualificação profissional, pedreiros, carpinteiro, mestre de açúcar, entre outros, tais especializações também podem ter dificultado o processo da alforria. Essa é uma suposição levantada por Mary Karasch em sua obra intitulada A vida dos escravos no Rio de Janeiro (1808-1850) publicada aqui no Brasil em 2000. Entretanto, sua suposição merece uma breve consideração.

De fato, essa suposição levantada há alguns anos tem sua lógica. Muitos dos senhores escravistas possuíam grandes contingentes de cativos masculinos, e inclusive, uma parcela considerável se especializavam em algum tipo de trabalho para aumentar os jornais dos seus donos, o que na verdade acontecia. Em contrapartida, os preços desses mesmos escravos sofriam um considerável aumento, o que poderia sim, dificultar a taxa de alforria. Mas, um outro fator interessante levantado por Sidney Chalhoub no livro Visões da Liberdade: uma história das últimas décadas na corte, revela que uma possível resposta para os altos índices da taxa de alforria entre as mulheres poderiam está ligada também ao fator descendência. Segundo o autor, as mulheres escravas tinham a preferência pela liberda- 
de, pois os seus filhos já poderiam nascer livres, o que incidiria no rompimento indireto da escravidão. No entanto, tais características são peculiares a cada região.

\section{O perfil das cartas de alforria em Laranjeiras:}

Em Laranjeiras, alguns períodos foram de verdadeiro equilíbrio entre homens e mulheres quanto ao recebimento das alforrias. Um exemplo disso foi o resultado dado a partir da análise de 12 cartas para o período de 1843 a 1845 . Neste caso, tanto os homens quanto as mulheres receberam os mesmos números de cartas de liberdade. Em dados gerais, vejamos as alforrias em Laranjeiras no século XIX:

QUADRO 1: Sexo dos escravos alforriados em Laranjeiras durante o século XIX

\begin{tabular}{|c|c|c|}
\hline SEXO & QUANTIDADE & FREQUENCIA \\
\hline Homens & 12 & $44,46 \%$ \\
\hline Mulheres & 15 & $55,54 \%$ \\
\hline Total & 27 & $100 \%$ \\
\hline
\end{tabular}

Fonte: AJES, Livro de Notas da região de Laranjeiras, $\mathrm{n}^{\circ}$ geral: 250

Nesta amostra as mulheres representam (55,54\%) do total, uma ligeira vantagem nas concessões em comparação aos escravos do sexo masculino (44,46\%). Mesmo que esta diferença seja pequena, o resultado comprova o que outros autores já afirmaram: as mulheres foram as mais beneficiadas no quesito das cartas de alforria. E em Laranjeiras, até o momento, o que se observa é o mesmo em comparação a outras regiões do 
Cadernos de Clio, Curitiba, n. ${ }^{\circ}$ 4, 2013

Brasil. Lembrando que esse é um resultado elaborado exclusivamente a partir da análise de cartas de liberdade, podendo esses dados sofrer algumas alterações ao serem analisados outros documentos.

Quanto à idade, somente em 11 cartas tais características estiveram presentes, e aparentemente essas idades não ultrapassaram a casa dos 55 anos, quando o escravo ainda estava apto para o trabalho pesado nas lavouras de cana-de-açúcar. O que nos leva a perguntar: por quais motivos os senhores no ato da alforria não acrescentavam a idade desses futuros libertos? Segundo Mary Karasch (2000), os motivos utilizados pelos senhores para não colocar a idade desses escravos talvez seja explicado por esses representarem os inválidos e/ou por serem idosos. Essa leva de cativos poderia, para algumas famílias, talvez, gerar gastos extras. O escravo que outrora trouxera um bom lucro para os senhores de engenho, agora não mais tinha serventia ${ }^{5}$.

As leituras dessas cartas nos revelam um valioso indicio de quem concedia a liberdade aos escravos. Do total do material analisado na pesquisa, foram encontradas 16 alforrias em que os senhores estavam presentes. Já as senhoras participaram diretamente de 08 concessões. Nos documentos foram encontradas também 03 cartas de alforrias concedidas por casais. Inicialmente, o que chama a atenção é a participação da mulher que, de certa forma não foi inexpressiva, chegando ao total de (29,62\%). Neste caso, não foi incluso o grupo das mulheres que alforriaram juntamente com os seus maridos. Acreditamos que nessa sociedade, moldada

\footnotetext{
${ }^{5}$ Os textos das cartas de liberdade não dão acesso aos transcursos da vida desses escravos.
} 
por traços masculinos, seguindo um modelo patriarcal, essas senhoras tiveram uma participação muito importante no ato da alforria dos cativos. Um exemplo disso é o registro da carta de liberdade conferida ao "mulato” de nome Gonçalo, por seu senhor Antônio José de Souza e sua mulher:

Dizemos nós marido e mulher, Antônio José de Souza e Dona Joanna Francisca do Sacramento que entre os mais bens que possuímos, he bem assim hum mulato de nome Gonçalo ao qual com a condição de nos acompanhar em quanto formos vivos, o forramos, [sic]gosará o dito mulato [...] obedecendo a condição da sua liberdade como de nascera de ventre livre[... $]^{6}$

Entre os homens que passaram alforrias, já poderíamos esperar uma maior participação no ato de libertar os escravos em relação às mulheres, eles estiveram presentes em $(59,25 \%)$ dos casos. No caso da profissão dos senhores, poucas foram as ocasiões em que tais ocupações apareceram, são eles, doutores, advogados, delegado, tenente, coronel e major, e em um único caso, há uma referência de uma madre.

A tipologia das cartas de alforria apresenta dados fundamentais para compreender traços da dinâmica interna da região analisada. Tais resultados informam, por exemplo, se o local oferecia condições para que os cativos obtivessem maiores chances de liberdade.

AJES. Carta de liberdade referente ao período de 1843-1845, $\mathrm{n}^{\circ}$ geral: $250,4^{\circ}$ Livro de Notas do Tabelionato de Laranjeiras, fl. 128. 
Cadernos de Clio, Curitiba, n. ${ }^{\circ}$ 4, 2013

QUADRO 2: Modalidades das cartas de alforria passadas em Laranjeiras (séc. XIX)

\begin{tabular}{|c|c|c|}
\hline MODALIDADES & QUANTIDADE & FREQUENCIA \\
\hline Condicionadas & 10 & $37,04 \%$ \\
\hline Incondicionadas & 05 & $18,52 \%$ \\
\hline Compradas & 12 & $44,44 \%$ \\
\hline Total & 27 & $100 \%$ \\
\hline
\end{tabular}

Fonte: AJES, Livros de Notas da região de Laranjeiras, $\mathrm{n}^{0}$ geral: 250.

Em geral, as cartas de alforria estão divididas em três grandes grupos: cartas condicionadas, incondicionadas e compradas. As cartas condicionadas e incondicionadas eram passadas de forma "gratuita". No entanto, a carta condicionada não impedia que o escravo dependente a cláusulas restritivas pagasse pela mesma. Essa concessão de forma "gratuita” era geralmente colocada de maneira condicional, possuindo algumas disposições limitativas, impedindo o escravo de ganhar sua liberdade imediatamente. Esse é o caso do registro de liberdade da "mulatinha" de nome Maria por seu senhor José Araujo e sua mulher (não identificada):

Dizemos nós abaixo assinados, que somos senhores e possuidores de huma mulatinha de nome Maria com idade de dois meses e filha de nossa escrava Martha, e com a condição de nos acompanhar durante as nossas vidas, e daí em diante gosará de sua liberdade como que nascesse do ventre de sua mãe forra $[\ldots]^{7}$

${ }^{7}$ AJES. Carta de Liberdade referente ao período de $1843-1845, \mathrm{n}^{\circ}$ geral: $250,4^{\circ}$ Livro de Notas do Tabelionato de Laranjeiras, fl. 92 
Esse tipo de alforria fazia com que o dito "liberto" servisse aos seus donos por muito tempo, constituindo mais uma estratégia de luta dos senhores pelo controle do escravo. De acordo com Fátima Novaes Pires (2006), o uso dessa estratégia era mais frequente em locais cujo poder econômico era mais razoável. Já Kátia Mattoso critica essa forma de alforria:

Será realmente 'gratuita', como gostam de escrever certos senhores, essa liberdade concedida sob a condição de o forro permanecer escravo enquanto vivos forem o senhor, ou seu filho, sua irmã ou qualquer dos outros membros da família? Na verdade, ela é paga muito caro [sic], é sempre revogável e torna o escravo libertável ainda mais dependente, pois ele sabe que a menor desavença, um instante de mau humor, pode pôr abaixo o edifício duramente construído de sua futura libertação (MATTOSO, 1990, p. 184).

A revogação das cartas de alforria foi extinta em 1865, impossibilitando o uso dessa estratégia encontrada pelos senhores de fazer retornar ao cativeiro o escravo que já tivesse sido alforriado. Paralelo a essa modalidade, existiam ainda as cartas incondicionadas, onde os senhores deixavam bem claro que agiam de acordo com a "generosidade e a estrita equidade”. No entanto, não podemos colocar essas atitudes como atos benevolentes de donos de escravos. Esses senhores poderiam utilizar dessas estratégias para assegurar trabalhos gratuitos ou a pequenos custos, pensando também que muitas dessas conquistas eram adquiridas através de várias estratégias de lutas e negociações entre senhores e escravos. Sem contar que nessas cartas poderiam estar o contingente de escravos idosos e/ou inválidos. 
Cadernos de Clio, Curitiba, n. ${ }^{\circ}$ 4, 2013

Muitos escravos também conseguiram comprar suas alforrias em Laranjeiras. A maioria desses escravos que conseguia juntar um pecúlio deveria ter trabalhado muito em outras ocupações, além das suas obrigações nos engenhos de açúcar. Analisando algumas obras que retratam Sergipe, somente em uma foi citada o termo "escravo ao ganho ou de ganho": Escravidão, liberdade e resistência em Sergipe: Cotinguiba, 1860-1888, de Sharyse Piroupo. Então, como os escravos sergipanos da região de Laranjeiras conseguiram juntar o dinheiro suficiente para comprar a própria alforria, ou a de seus familiares? É provável que esses escravos tivessem suas próprias roças, cedidas pelos senhores e em dias de descanso saíssem para vender nas feiras e em outras localidades.

O preço das alforrias no período abordado neste artigo nos dá um pequeno indício das quantias gastas pelos escravos para obter a liberdade. O menor valor encontrado de um escravo em Laranjeiras foi localizado no registro de liberdade do africano Bonifacio, que custou 500 mil réis e foi pago em moeda corrente. E o valor mais alto que foi visto até o momento está no registro de alforria passada para outro africano, de nome Guilherme no ano de 1859, tendo um pouco mais de trinta e cinco anos de idade, paga também em moeda corrente, e à vista o seu valor foi de 1 conto e 400 mil réis.

Algumas dessas cartas compradas foram obtidas através de pagamentos a prestação ou em "banda”, como vem escrita em alguns documentos. Como é o caso do “preto” Firmino de nação nagô, trinta e cinco 
anos, que pagou por uma banda o preço justo de um conto de réis. ${ }^{8}$ Esse escravo só foi liberto por uma parte e a outra "banda” ficou sujeita à exmulher do seu antigo dono. Talvez, como pensou Sharyse Piroupo (2006), o escravo que conseguisse pagar ao menos, metade do valor de sua alforria, estaria numa situação melhor em relação a outro cativo. Pois, livrando-se em parte do cativeiro, servindo ao seu senhor não mais em período integral, o escravo teria mais tempo de cair ao ganho, e conseguir assim pagar a outra metade por um tempo mais curto, gozando da liberdade o mais rápido possível.

Várias foram as denominações escravas nas cartas de alforria encontrada nos Livros de Notas do Tabelionato de Laranjeiras nos oitocentos. Preto, nagô, africano, crioulo, entre outros. É importante salientar que na tabela abaixo, foram levadas em conta todas as denominações encontradas nas cartas de alforria, pois era comum que em uma única carta os libertadores (senhores) denominassem os escravos de maneiras diferentes, como no caso da parda Maria de Nazareth,

Digo eu abaixo assignado que entre os mais bens que possuo livres e desenbargados, he bem assim huma mulatinha de idade de trinta annos por nome de Maria de Nazareth, que me deu minha (ilegível) religiosa do Convento de sociedade de madre Joana Josefa de são Pedro [... $]^{9}$ [grifo nosso].

\footnotetext{
${ }^{8}$ AJES. Essa carta foi resultado de uma partilha de bens que foi deixada pela Dona Francisca Maria de Jesus e Mello. O dito escravo comprou somente a metade de sua liberdade. Laranjeiras 1859, $\mathrm{n}^{\circ}$ geral: 250, fl. 84.

${ }^{9}$ Registro de carta de liberdade da parda Maria de Nazareth, a qual lhe foi conferida, por sua senhora madre Dona Antonia Maria Mercez no ano de 1844. AJES, Cx. 250, fls. 111-112.
} 
Cadernos de Clio, Curitiba, n. ${ }^{\circ}$ 4, 2013

Neste registro a mesma escrava Nazareth recebe duas denominações diferentes, parda e mulatinha. Apesar das duas designações a escrava foi forra como se de ventre livre tivesse nascido e sem nenhuma restrição. O quadro abaixo revelará as denominações encontradas nas cartas de liberdade de Laranjeiras nos oitocentos:

QUADRO 3: Denominações dos escravos alforriados em Laranjeiras (séc. XIX).

\begin{tabular}{|c|c|c|}
\hline DENOMINAÇÃO & QUANTIDADE & FREQUÊNCIA \\
\hline Africano & 02 & $6,66 \%$ \\
\hline Crioulo & 06 & $20 \%$ \\
\hline Mulato & 09 & $30 \%$ \\
\hline Nagô & 02 & $6,66 \%$ \\
\hline Pardo & 05 & $16,66 \%$ \\
\hline Preto & 03 & $10 \%$ \\
\hline Cabra & 01 & $3,34 \%$ \\
\hline Não Consta & 02 & $6,66 \%$ \\
\hline Total & 30 & $100 \%$ \\
\hline
\end{tabular}

Fonte: AJES, Livros de Notas da região de Laranjeiras, $\mathrm{n}^{0}$ geral: 250.

No quadro acima, é possível ver que a denominação “mulato” está na maioria das cartas, seguida pelo termo “pardo”. Tal prática está bem representada pela historiografia brasileira. Kátia Mattoso, em sua obra Ser escravo no Brasil, publicada pela primeira vez em 1982, e Mary Karasch em A vida dos escravos no Rio de Janeiro (1808-1850), informam que os escravos nascidos no Brasil foram os mais beneficiados na hora da alforri- 
a. Para tanto, em estudos referentes a outras regiões brasileiras, é possível perceber que os africanos também tiveram algumas oportunidades de conseguir a liberdade, sendo que entre eles, as mulheres tiveram uma relevante vantagem sobre os homens.

\section{Conclusão}

Portanto, no decorrer da pesquisa foi possível perceber, através da análise descritiva dessas cartas de alforrias, várias características fundamentais para o entendimento do processo de liberdade dos escravos na região de Laranjeiras nos oitocentos. Nas amostras, as mulheres levaram vantagem em relação aos homens quanto à concessão das alforrias; no total, elas receberam 15 concessões de liberdade. Quanto à participação dos senhores, já era esperada a presença maior do homem frente às concessões. Apesar da significativa participação feminina nessas concessões de liberdade. Em relação à idade dos escravos, somente em 11 cartas tal característica apareceu. No entanto, a média de idade desses cativos não ultrapassou a casa dos 55 anos.

Dessa forma, o escravo teve maiores possibilidades de comprar a sua própria liberdade, afirmação esta comprovada pelos dados obtidos na análise. Outra conclusão foi que os escravos denominados “mulatos” tiveram uma maior possibilidade de conseguir a alforria. Entre as 27 cartas colhidas, eles apareceram 09 vezes, cerca de 30\% do total.

A liberdade por esse instrumento legal representou para os escravos uma “concessão” que se concretizou através de lutas, trabalhos e humilhações frente ao sistema escravocrata da época. A quantidade significativa de cartas de alforrias que foram condicionadas a cláusulas restritivas, im- 
possibilitando a imediata liberdade dos escravos, comprova firmemente essa triste e dura realidade de tantos “pretos”, "nagôs”, “mulatos” e “crioulos” que viveram nos engenhos laranjeirenses do século XIX.

\section{Fontes:}

Arquivo Judiciário do estado de Sergipe:

AJES- Livro de Notas da freguesia de laranjeiras, Caixa:01, Acervo:01, $\mathrm{N}^{\circ}$ Geral: 250, Período: 1831-1917, Módulo: II.

\section{Bibliografia:}

AMARAL, Sharyse Piroupo do. Escravidão, liberdade e resistência em Sergipe: Cotinguiba,1860-1888. Salvador, 2007, (Tese de doutorado).

CHALHOUB, Sidney. Visões da Liberdade: uma história das últimas décadas da escravidão na corte. São Paulo, Companhia das Letras, 1990.

KARASCH, Mary. A vida dos escravos no Rio de Janeiro (1808-1850). São Paulo, Companhia das Letras, 2000.

LARA, Silva H. Campos da violência: escravos e senhores na capitania do Rio de Janeiro, 1750-1808. Rio de Janeiro, Paz e Terra, 1988.

MATTOSO, Kátia M. de Queirós. Ser Escravo no Brasil. São Paulo, Ed. Brasiliense, $2^{\circ}$ ed. (1 1982) 1988.

MOTT, Luiz. Sergipe Del Rey-população, econômia e sociedade. Aracaju, Fundesc, 1986.

NUNES, Maria Thétis. Sergipe Colnial I, Aracaju, Universidade Federal de Sergipe; Rio de Janeiro, Tempo Brasileiro, 1989

PIRES, Maria de Fátima Novaes. Cartas de Alforria: "para não ter o desgosto de ficar em cativeiro”. Revista Brasileira de História, vol. 26, n ${ }^{52}$, São Paulo, 2006.

SANTOS, Ynaê Lopes dos. Além da Senzala: Arranjos escravos de moradia no Rio de Janeiro (1808-1850), São Paulo, (Dissertação de Mestrado). 